\title{
LAS RENTAS REALES EN LA PROCURACIÓN DE ORIHUELA, 1305-1324
}

\author{
Juan Antonio BARRIO BARRIO \\ Universidad de Alicante
}

\section{EL PATRIMONIO REAL A PRINCIPIOS DEL SIGLO XIV}

Tras la conquista del reino de Murcia en 1296 Jaime II unió las villas reales más importantes como Orihuela, Alicante y Guardamar a la Corona de Aragón. La firma de los tratados de Torrellas y Elche en 1304 y 1305 se plasmó en la definitiva incorporación a la Corona de Aragón de los territorios situados entre Biar y el río Segura. Quedando dentro del patrimonio real localidades como Alicante, Guardamar, y Orihuela. Ello suponía la posibilidad de contar con una mayor cobertura territorial hacia el Mediterráneo con puertos como el de Alicante y el incremento consolidado de la renta recaudada por la Corona por la incorporación al patrimonio real de tierras, rentas, monopolios, jurisdicciones, etc. Coincidiendo en esta franja cronológica con la anexión temporal a la Corona de localidades tradicionalmente señoriales como Elche y Crevillente.

El estudio de las rentas reales en el reinado de Jaime II es una cuestión todavía por abordar, a pesar de los recientes avances en el conocimiento del patrimonio real de la Corona de Aragón en época de Jaume I, Alfonso el Casto, Alfonso el Benigno,

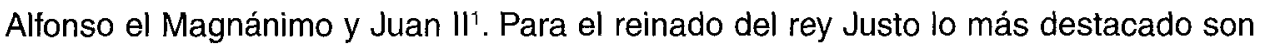

1 GUINOT, E., “El patrimoni reial al Pais Valencià a inicis del segle XV», Anuario de Estudios Medievales, 22 (1992), pp. 581-639. Donde recoge la bibliografía puntual de los estudios sobre el patrimonio real en estos reinados. Para la fiscalidad regia en la Corona de Aragón entre los siglos XII al XIV son imprescindibles los trabajos de Manuel SÁNCHEZ MARTíNEZ, "La fiscalidad real en Cataluña (siglo XIV)", Anuario de Estudios Medievales, 22 (1992), pp. 341-375. ld. "La evolución de la fiscalidad regia en los países de la Corona de Aragón (c.1280-1356)», Europa en los umbrales de la Crisis (1250-1350), Pamplona, 1995, pp. 393-428. Id. El naixement de la fiscalitat d'Estat a Catalunya: segles XII-XIV. Vic, 1995. 
los estudios de Ferrer i Mallol sobre la renta mudéjar ${ }^{2}$ y sobre la organización de la bailía de Orihuela ${ }^{3}$ y la aproximación al estudio de las finanzas de la Corona a principios del siglo XIV realizada por Guilleré .

Nuestro objetivo es realizar un análisis de las rentas reales ordinarias en la procuración de Orihuela entre 1305 y 1324, período comprendido entre el tratado de Elche y la separación de Elche del patrimonio real, a partir de las cuentas conservadas para los años 1316-13245.

Dentro de la organización administrativa emprendida tras la partición del reino de Murcia entre la Corona de Aragón y Castilla por el tratado de Torellas de agosto de 1304, Jaime II nombro al que era baile general del reino de Murcia Ferrer Descortell, nuevo baile general de las tierras dellà Xixona ${ }^{6}$. El baile general era el responsable de la administración del patrimonio real. Tenía que recibir las rentas y los impuestos reales y pagar los gastos de la Corona en la demarcación que administraba, y presentar sus cuentas al Maestro Racional ${ }^{7}$, que era el contador supremo del reino, que fiscalizaba las cuentas de todos los oficiales dependientes de la hacienda regia, como los bailes locales y sus lugartenientes ${ }^{8}$.

Para el estudio de las rentas reales de la bailía dellà Xixona he utilizado como principal fuente las cuentas de la administración de la bailía entre 1316 y 1324 conservadas en el Archivo de la Corona de Aragón y en el Archivo del reino de Valencia9.

Las cuentas del Baile Joan Rolf comprenden desde el día 1 de Mayo del año 1316 hasta diciembre de 1317. Vecino de Alicante había asumido el cargo en agosto de

2 FERRER i MALLOL, Ma.T., Els sarrains de la Corona catalano-aragonesa en el segle XIV. Segregació i discriminació, Barcelona, 1987. Id., La frontera amb I'Islam en el segle XIV. Cristians i sarraïns al Pais Valencià. Barcelona, 1988. Id., Les aljames sarraïnes de la Governació d'Oriola en el segle XIV, Barcelona, 1988.

3 FERRER I MALLOL, Ma.T., "La Batllia general de la part del regne de Valencia dellà Xixona", Anales de la Universidad de Alicante. Historia Medieval, 6 (1987), pp. 279-309.

4 «Les finances de la Couronne d'Aragon au debut du XIV siecle (1300-1310)", Estudios sobre renta, fiscalidad y finanzas en la Cataluña Bajomedieval, Barcelona, 1993, pp. 487-507.

5 Para aquilatar el tema he preferido no incluir el estudio de los subsidios y contribuciones extraordinarias realizadas por las villas reales en el período, como las subvenciones aportadas por las villas de Guardamar, Alicante, Elche y Orihuela a la campaña de Cerdeña comentadas en HINOJOSA MONTALVO, J. y BARRIO BARRIO, J.A., «Las Sisas en la Gobernación de Orihuela durante la Baja Edad Media», Anuario de Estudios Medievales, 22 (1992), pp. 535-579.

6 FERRER I MALLOL, Ma .T., «La Batllia general de la part del regne de Valencia delià Xixona...», pp. 282-283.

7 Ibídem, pp. 279-280.

8 FERRAZ PENELAS, F., Que fue el Maestre Racional. Valencia, 1977, p. 4. MONTAGUT I ESTRAGUÉS, T., El Mestre Racional a la Corona d'Aragó (1283-1419). 2 vols. Barcelona, 1987.

9 Disponemos de las cuentas del año 1316, 1317 y 1324 conservadas en el Archivo de la Corona de Aragón en la sección Maestre Racional, Reial Patrimoni, correspondiente a los registros 1701 y 1702. Mientras que las cuentas de los años $1318,1319,1320,1321$ y 1322 se encuentran en el Archivo del reino de Valencia, en un cuaderno incluido en un registro de la sección de Bailía. 


\section{LOS INGRESOS. LA PARTICIPACIÓN DE LAS VILLAS REALES EN LAS REN- TAS DE LA CORONA}

Uno de los aspectos fundamentales para el estudio del patrimonio real, es conocer el nivel de ingresos, a través de la valoración de la aportación de cada una de las villas reales del territorio, señalando en cada localidad las exacciones que se percibían, el valor de las mismas y la contribución global.

\section{Las rentas de Elche}

Como afirma Ferrer i Mallol Elche fue una villa real bajo dependencia de la Corona desde 1305 a 1324. Destaco en este período ente las villas reales como la más rica e importante de todas ${ }^{12}$. Contaba con la comunidad sarracena más numerosa de la procuración de Orihuela lo que se refleja en el nivel de ingresos, en comparación con lo que se recaudaba en las localidades de Alicante, Orihuela y Guardamar con población cristiana predominante. Una de las rentas más elevadas que recaudaba la Corona en Elche y por ende en todo el territorio de la procuración era la denominada «renta de moros", que comprendía una amplia gama de tributos sobre el individuo y la comunidad y sobre la producción.

La Corona recaudaba en Elche la mayor parte de las rentas en el territorio procuratorial, suponiendo porcentualmente en todo el período estudiado valores entre el 53 y el $79 \%$ sobre el total. Recayendo una buena parte de estas cargas fiscales sobre la comunidad mudéjar. Procedían en su mayor parte de una amplia y variada gama de exacciones sobre el individuo y la comunidad, sobre la posesión de los medios de producción y transformación, sobre la actividad comercial y mercantil ${ }^{13}$ y sobre algunos monopolios cuya gestión se arrendaba anualmente.

Rentas de los moros de Elche. Bajo este concepto se recaudaban, en una sola partida, una serie de rentas sobre la comunidad mudéjar de Elche y que en el período

10 FERRER I MALLOL, Mํ.T., "La Batllia general de la part del regne de Valencia dellà Xixona...", pp. 286-287.

11 Ibídem, pp. 287-288.

12 FERRER I MALLOL, Mํ.T., Les aljames sarraïnes..., p. 11.

13 Seguimos básicamente la tipología establecida por E. GUINOT en Feudalismo en expansión en el norte valenciano. Antecedentes y desarrollo del señorío de la Orden de Montesa. Siglos XIII y $X I V$, Castellón, 1986, y utilizada por J. HINOJOSA MONTALVO en sus trabajos sobre fiscalidad mudéjar: “Crevillente: una comunidad mudéjar en la Gobernación de Orihuela en el siglo XV», Actas del IV Simposio Internacional de Mudejarismo, Teruel, 1992, pp. 307-317. Id., La morería de Elche en la Edad Media, Teruel, 1994. Id., "Señorío y fiscalidad mudéjar en el reino de Valencia", Actas del V Simposio Internacional de Mudejarismo, Teruel, 1991, pp. 105-134. Id., "La renta feudal de los mudéjares alicantinos", Señorio y Feudalismo en la Península Ibérica. (ss. XII-XIX), Zaragoza, 1993, vol. II, pp. 105-129. 
estudiado fueron colectadas por Alfons Guillem. Era la renta más importante de Elche. En el libro de cuentas del baile se especifica el significado de cada exacción ${ }^{14}$ :

- El atzaque. Se pagaba por el ganado pequeño dos dineros por cabeza, posiblemente ovino y cabruno. En 1315 ascendió a 500 sueldos anuales. A partir de 1316 la renta quedo integrada en el monto global del tributo de los moros de Elche.

- El almagram. Tributación sobre la posesión de la tierra según la extensión y la calidad de la misma.

- El cabezaje. Impuesto que abonaba cada musulmán varón mayor de dieciséis años y las mujeres viudas. La tarifa establecida era de 5 sueldos por cabeza.

- La alfarda. Era uno de los impuestos comunitarios más importantes de las comunidades mudéjares del reino de Valencia. Consistía en una cantidad fija anual que cada aljama pagaba al rey.

- La alfatrà. Era un impuesto de capitación que gravaba a todos los miembros de la comunidad musulmana con una tarifa de un almud de cebada.

- Los diezmos de la vendimia, del trigo, de la alcandia, de la cebada que pagaban los musulmanes de Elche.

- La alhabeç de las mezquitas. Era una peita que los musulmanes entregaban para la mezquita.

- La albayat. Colectado sobre la tierra de secano que sembraban los mudéjares. En 1315 por este concepto se recaudaron 100 sueldos $^{15}$.

- La venta del agua de Marchena y de las cuatro alquerías utilizada para regar tierras de moros, generaba una renta a la Corona, individualizada en 1315 por un importe de 4.000 sueldos anuales ${ }^{16}$, pero que en las cuentas del período estudiado esta englobada dentro del grupo de exacciones de los moros de Elche.

- Las gallinas. Cada casa habitada por musulmanes debía entregar una gallina o su equivalente en dinero, 6 dineros, al rey cada año ${ }^{17}$.

Diezmos. En 1316 y 1317 se recaudaron una serie de diezmos sobre la producción agraria por separado de la denominada renta de los moros. El diezmo o alfatrà de la cebada consistió en una gravamen de 2 cahíces de cebada por cada centenar. También se cobraron por separado el diezmo del trigo, de la alcandia y del aceite ${ }^{18}$.

Herbaje. Impuesto que se pagaba por la utilización de los pastos ${ }^{19}$. Con una tarifa en 1316 de 11 sueldos por cabeza ${ }^{20}$.

Carnaje. Consistía en una parte del diezmo de los animales nacidos durante el año ${ }^{21}$.

14 La definición de cada una de estas rentas en FERRER I MALLOL, Mª .T., Les aljames sarraïnes...

15 Ibídem, p. 145.

16 FERRER I MALLOL, Mํ. T., Les aljames sarraïnes..., p. 145.

17 Ibídem, p. 141.

18 A.C.A. Real Patrimonio, Maestro Racional, Reg. 1701.

19 Del derecho de herbaje cobrado en 1323 se ha descontado el salario del colector, aunque en las cuentas no aparece especificada la cantidad.

20 A.C.A. Real Patrimonio, Maestro Racional, Reg. 1701, f. 3r.

21 En el reino de Valencia era la cuarta parte. GUINOT, E., "El patrimoni reial al Pais Valencià....", p. 598. Desconocemos que porcentaje se aplicaba en Elche, ya que desde la conquista de Jaime II en 
Quirat. Era un derecho que cobraba la Corona a los mudéjares en las villas del reino de Valencia dellà Xixona por la entrada y salida de mercancías ${ }^{22}$. Según las cuentas de 1316 era el derecho que pagaban los moros por todo lo que compraban y vendían. Además en esta renta se cobraban los censos de tiendas, molinos, hornos, baños y otros derechos y caloñas ${ }^{23}$. Era la segunda renta más importante, y produjo entre 1316 y 1319 ingresos muy superiores a los percibidos por el almojarifazgo ${ }^{24}$.

De la cantidad que recibía el baile en nombre del rey se detraía una cantidad que tomaba el colector de la renta en concepto de retribución y otra por las cantidades que se destinaban a gastos de obras y mantenimiento en los molinos, hornos, tiendas, baños, etc. ${ }^{25}$.

Almojarifazgo. Era el mismo impuesto que el quirat, pero con el nombre de almojarifazgo gravaba a los cristianos. Definido en las cuentas como el derecho que los mercaderes cristianos pagaban en la aduana de Elche ${ }^{26}$. Bajo este concepto se cobraban otros censales que el rey tenía en Elche ${ }^{27}$. Como en el quirat en la cantidad ingresada en las arcas reales se restaba lo que debia cobrar el colector ${ }^{28}$.

En las cuentas de 1318 aparece una anotación que indica que el almojarifazgo lo pagaban también los judíos: «... el dret que alcuns cristians e juheus pagaran el dit any en la dita duana $a b$ alcuns censals...»29.

Desde 1320 quirat y almojarifazgo, se cobraron bajo un mismo concepto denominado aduana de Elche $^{30}$.

Derecho del puerto del Cap del Aljup. Se cobraba en el puerto del Cap del Aljup de Elche $^{31}$ a cristianos, moros y judíos por las mercancías que cargaban.

el cobro de la pena del quart la Corona aplico una reducción de la misma a la décima parte, porcentaje que también podía afectar al cobro de ciertas rentas.

22 FERRER I MALLOL, Ma.T., Les aljames sarraïnes..., p. 146.

23 Ibídem, pp. 149-150.

24 A partir de 1320 ambas rentas aparecen unidas como aduana de Elche.

25 A.C.A. Real Patrimonio, Maestro Racional, Reg. 1701, f. 1r.

26 Para el estudio del almojarifazgo en Elche y Alicante vid. HINOJOSA MONTALVO, J., «Un arancel comercial en Alicante y Elche durante la Baja Edad Media: el derecho de Aduana", Anuario de Estudios Medievales, 23 (1993), pp. 57-74.

27 A.C.A. Real Patrimonio, Maestro Racional, Reg. 1701, f. 1r.

28 En 1316 por el cobro del almojarifazgo el colector Bernat Saverdú, que además regentaba la escribanía de la aduana de Elche, recibió por siete meses 58 sueldos 4 dineros, en concepto de los 100 sueldos anuales que cobraba como colector. A.C.A. Real Patrimonio, Maestro Racional, Reg. 1701, f. 1r. FERRER I MALLOL, M‥T., "La Batllia general de la part del regne de Valencia dellà Xixona...".

29 A.R.V. Bailía, Apéndice 61, f. 300r.

30 En 1324 las rentas de la aduana de Elche fueron arrendadas por 17.200 sueldos de los que hubo que descontar por salarios de los guardas que vigilan los caminos 1737 sueldos, por obras y otros gastos 322 sueidos 4 dineros, por las franquicias comerciales concedidas a los vecinos de Barcelona, Mallorca y Gerona 1.865 sueldos 4 dineros y por cantidades pendientes por dicho concepto del año pasado 364 sueldos 9 dineros. A.C.A. Real Patrimonio, Maestro Racional, Reg. 1702.

31 Sobre el puerto medieval de Elche vid. HINOJOSA MONTALVO, J., «El Cap del Aljup, puerto medieval de Elche", Mayurqa. Homenatge a Álvaro Santamaría, 23, Palma de Mallorca, 1989, I, pp. $311-374$. 
"... ço es quels crestians moros e juheus estranys e privats paguen al dit port per les coses e mercaderies que hi carreguen..." ${ }^{32}$.

En 1315 la renta rendía una suma de 2.000 sueldos $^{33}$. En las cuentas de 1316 el colector de dicha renta era Bernat Despuig, que ejercía además la escribanía del puerto $^{34}$ y recibía 400 sueldos que se descontaban del importe recaudado por realizar ambas funciones.

En 1324 se arrendaron las rentas del puerto del Cap del Aljup a Alfonso Guillem por 1.550 sueldos. De esta cantidad la corona recibió una mínima parte que no alcanzo los 200 sueldos, ya que hubo que deducir una serie de gastos que tuvo el arrendatario:

- Por las franquicias comerciales concedidas por la Corona a los vecinos de Barcelona, Gerona y Mallorca 700 sueldos.

- Por el salario del Escribano del Puerto 400 sueldos.

- Por 75 moros que pasaron con el mensajero del rey de Granada con franquicia de pago 256 sueldos 8 dineros ${ }^{35}$.

Con el arrendamiento de las rentas del puerto de Elche la Corona continuo con la tendencia de arrendar las rentas de tipo comercial, como era habitual en Alicante y Orihuela.

Arrendamiento de la Albufera. La Albufera de Elche destaco por su aprovechamiento para actividades pesqueras. Entre 1316 y 1324 fue arrendada por la Corona ${ }^{36}$.

Tahurería. Monopolio que se arrendaba anualmente y que gravaba el juego legal que se celebraba en la tahurería. En 1307 las autoridades locales de Elche solicitaron a Jaime II la cesión de esta renta y la de la Albufera al municipio para poder destinar el importe de ambas, que los munícipes estimaban en torno a mil sueldos, para la reparación de las murallas de la villa. Petición que fue denegada ${ }^{37}$. La suma de las rentas de la tahurería y de la Albufera en las cuentas de los año 1316-1319 arroja una cifra que se aproxima mucho a la que utilizaron las autoridades municipales de Elche en su solicitud del año $1307^{38}$. De los ingresos de la tahurería se descontaban todos los años 40 sueldos en concepto del alquiler del local donde se jugaba.

Judíos de Elche. Era una renta que pagaban los judíos de Elche y los de Orihuela. Consistía en una tasa anual fijada sobre ambas juderías y que ascendía a 1050 sueldos, pero que fue rebajada por Jaime II a 800 sueldos, de los que 500 correspondían

32 A.C.A. Real Patrimonio, Maestro Racional, Reg. 1701, f. 1v.

33 FERRER I MALLOL, M…, Les aljames sarraïnes..., p. 149.

34 FERRER I MALLOL, M‥T., "La Batllia general de la part del regne de Valencia dellà Xixona...", p. 303.

35 A.C.A. Real Patrimonio, Maestro Racional, Reg. 1702, f. 3v.

36 En 1316 se arrendó con el march por 1.100 sueldos a un vecino de la localidad.

37 FERRER I MALLOL, M‥T., Organització i defensa d'un territori fronterer. La Governació d'Oriola en el segle XIV. Barcelona, 1990, pp. 167-168. Doc. no 58. (1307, diciembre), pp. 393-394.

38 A.C.A. Real Patrimonio, Maestro Racional, Reg. 1701. A.R.V., Bailía, Apéndice 61, ff. 300r$301 \mathrm{r}$. 
a los de Orihuela y 300 a los de Elche, aunque posteriormente, sobre todo a partir de las cuentas de 1320 fue modificado el gravamen proporcional de cada judería pagando los de Orihuela 530 y los de Elche 270.

"Item es çert que los juheus de Oriola e d'Elx solien donar al senyor Reyu per tribut cascun any Mille $L$ solidos dels quals mostraren carta de gracia del dit senyor Rey que no fossen tenguts de pagar per cascun any entre tots mas DCCC sol. dels quals quels DCCC solidos se avengren en axi quels juheus d'Oriola pagasen los D. solidos..." ${ }^{39}$.

Alquería de Beniamor. La alquería de Beniamor a principios del siglo XIV pertenecia al arráez de Crevillente y fue concedida por Jaime II en 1320 a Acard de Mur ${ }^{40}$. En 1318 en las cuentas del Baile una anotación indica que «... veni la alqueria de Beniamor en lo terme de d'Elx la qual era del senyor de Crivillen ensemps ab un Reyal qui es en lo dit loch ço es la renda per cascun any. $\mathrm{MCCl}$ sous». A continuación la siguiente entrada refiere que el Real fue establecido a Alfonso Guillem «ab entrada» de 320 sueldos y con un censo anual de 150 sueldos $^{41}$. En 1320 por la alquería de Beniamor se recaudaron 300 sueldos 3 dineros.

Rentas judiciales de la bailía. Entre las rentas judiciales recaudas por el baile en Elche, destacar la multa impuesta en 1316 a Ricardo Trever, patrón de una nave que cargo mercaderías con la promesa de no llevarlas a tierra de enemigos y las desembarco en Almería y fue condenado por ello a pagar 4.000 sueldos. Restando 200 sueldos en los gastos de los hombres que acudieron a detenerlo sumo 3.800 sueldos.

En 1324 se impuso una multa de 400 sueldos a un patrón de nave de Orihuela que se había comprometido a no llevar sal desde el puerto de Cap de Cervera a Génova ni a Saona, pero fue denunciado por haber llevado la mercancía a la última locali$\operatorname{dad}^{42}$.

Renta judicial del justicia de Elche. De las multas y composiciones que cobraba el justicia se detraía el salario del justicia, el de su asesor y el del entregador, quedando la parte restante para el rey. Sólo hubo ingresos por este concepto en 1320 y ascendieron a 374 sueldos 4 dineros.

\section{Las rentas de Crevillente}

En 1296 Jaime Il incorporaba al patrimonio real de la Corona catalano-aragonesa villas como Alicante y Orihuela, mientras que en localidades señoriales se limito a aceptar la sumisión oficial de sus titulares. Tras asegurar en los primeros días de mayo el control de la comarca de Orihuela el ejército real se dirigió hacia Murcia iniciándose

39 A.C.A. Real Patrimonio, Maestro Racional, Reg. 1701, ff. $1 \mathrm{~V}-2 \mathrm{r}$.

40 FERRER I MALLOL, Mª.T., Les aljames sarraines..., p. 65.

41 A.R.V. Bailía, Apéndice, 61, f. 300.

42 A.C.A. Real Patrimonio, Maestro Racional, Reg. 1702, f. 5 r. 
el 16 de mayo el sitio del castillo de Monteagudo que dominaba la capital y donde recibió el día 17 la sumisión oficial del arráez de Crevillente (Mahomat o Muhammad Abinhudell), titular del señorío de Crevillente y de los lugares de Albatera y de Cox ${ }^{43}$.

Crevillente y Aspe se mantuvieron como señorío feudal respetado por Jaime II, ya que garantizo en 1296 al arráez Muhammad I y a su sucesor la continuidad al frente del señorío. En 1318 con la muerte del sucesor de Muhammad I el lugar fue incorporado al patrimonio real, para ser cedido en los años posteriores a miembros de la familia real. En mayo de 1322 Crevillente fue separado del patrimonio real y concedido al infante Pedro ${ }^{44}$.

Por esta breve incorporación al patrimonio real entre las rentas de Elche se recaudaron en los años 1318, 1319, 1320 y 1321 las rentas de Crevillente por valor de 12.604 sueldos, 30.147 sueldos, 25.448 sueldos y 18138 sueldos respectivamente.

\section{Las rentas de Alicante}

En Alicante y Orihuela a la hora de analizar la fiscalidad regia, se observan unas características propias que diferencian el régimen de exacción fiscal de la Corona en los territorios de la bailía dellà Xixona del de otras localidades del territorio regnícola, por el peso de la conquista castellana de la segunda mitad del siglo XIII y por el predominio de una población cristiana, que en la política repobladora de la monarquía castellana y de la catalano-aragonesa, en una zona de frontera, beneficio a los concejos de estas localidades con diversas exenciones fiscales sobre sus habitantes o con la concesión a las autoridades locales de rentas tan importantes como el tercio diezmo o el cabezaje. Alfonso X concedió al concejo de Alicante el cabezaje en $1261^{45}$ y que se aplicaba a principios del siglo XIV a las obras de las murallas ${ }^{46}$. Además de exenciones a mudéjares y judíos de la questia, alfarda, peita, etc., que luego fueron reconocidas por Jaime $\mathrm{II}^{47}$.

En Alicante predominaba una renta comercial como el almojarifazgo asociado a la importancia mercantil del puerto y dos monopolios como la tahurería y el almudín. La gestión del control del almojarifazgo y de la tahurería se arrendaba todos los años. Los mudéjares alicantinos también contribuían a las rentas de la Corona con impuestos como el cabezaje, la alquieda y las caloñas.

Almojarifazgo y aduana del puerto. Estos dos conceptos se incluyen en los libros de cuentas de la bailía por separado o unidos y siempre como principal tributo que se cobraba sobre la entrada y salida de mercancías y que debía gravar a los comerciantes cristianos, pero suponemos que también a los judíos y musulmanes ${ }^{48}$.

43 FERRER I MALLOL, M.T., «Notes sobre la conquesta del Regne de Múrcia por Jaume II (12961304)», en Homenatge a la memòria del Prof. Dr. Emilio Sáez. Barcelona, 1989, p. 33.

44 FERRER I MALLOL, M‥T., Les aljames sarraines..., pp. 16-22 y 33.

45 FERRER I MALLOL, M…, Organització i defensa d'un territori fronterer... p. 170.

46 FERRER I MALLOL, M‥T., Les aljames sarraïnes..., Doc. ํㅜ 80, pp. 243-244.

47 Ibidem, Doc. no 80, pp. 243-244.

48 A no ser que estuvieran exentos, ya que no aparece en las cuentas de Alicante el quirat. 
En las cuentas de 1316-1317 se registra como derecho de aduana del puerto de Alicante y fue arrendado en 1316 a Guillem Monserrat por 6.000 sueldos y en 1317 a Esteve de Rubí por 4.660 sueldos $^{49}$. En las de 1318, 1319, 1320 (4.120 sueldos), 1321 (4.000 sueldos) y 1322 (4.040 sueldos) como almojarifazgo y en las de 1324 como almojarifazgo y aduana al mismo tiempo. En 1324 y como había sucedido en Elche el valor del arrendamiento sufrió un importante descenso, ya que fue tasado en 2.860 sueldos, pero por las franquicias reales concedidas a los operadores mercantiles de Barcelona, Gerona y Mallorca la cantidad ingresada fue de 1356 sueldos 4 dineros, lo que suponía una considerable merma en los ingresos percibidos por la Corona por este concepto ${ }^{50}$.

Tahurería. Jaime II había concedido en 1304 al consell de Alicante para obras de las murallas el tercio diezmo de las rentas de la tahurería ${ }^{51}$, por lo que el consell de Alicante recibía una parte de las mismas. En los ingresos de 1317 le correspondió el $15 \%$ del valor del arrendamiento ${ }^{52}$.

Açoch y almudín. Las tiendas, obradores y el almudín eran locales que arrendaba la Corona cobrando por su cesión una cantidad anual. El almudín era el edificio donde particulares, mercaderes y panaderos podían almacenar o comercializar el trigo de la villa.

Marchs de plata. El march era el derecho que pagaban los arrendatarios al abonar la cantidad importe del arrendamiento que habían obtenido, y que era del 20 por mil respecto a la cantidad global del arrendamiento ${ }^{53}$.

Cabezaje moros. Como en Elche y el resto de localidades de la procuración era el impuesto que pagaba cada musulmán varón mayor de dieciséis años y las mujeres viudas. La tarifa establecida era de 5 sueldos por cabeza ${ }^{54}$. En Alicante este tributo gravaba a los moros "peons de la orta e del raval»" 55 .

Alquieda. El derecho de alquieda fue percibido por la Corona en Alicante sólo en el año 1319 y por valor de 450 sueldos. En un año en que paradójicamente no se recaudo la renta de caloñas, cabezajes, etc. de los mudéjares en Alicante. Es un tributo mudéjar que Ferrer i Mallol lo define como un impuesto comercial, posiblemente

49 A.C.A. Real Patrimonio, Maestro Racional, Reg. 1701, f. 17v. HINOJOSA MONTALVO, J., «Un arancel comercial en Alicante y Elche durante la Baja Edad Media: el derecho de Aduana", Anuario de Estudios Medievales, 23 (1993), pp. 57-74. FERRER I MALLOL, Mª ${ }^{\mathrm{a}}$.T., Les aljames sarraïnes..., p. 148.

50 A.C.A. Real Patrimonio, Maestro Racional, Reg. 1702, f. $1 \mathrm{r}$.

51 FERRER I MALLOL, M‥T., Organització i defensa d'un territori fronterer... p. 170.

52 La tahurería de Alicante fue arrendada en 1317 a Ramón de Montagut por 1650 sueldos de los que la Corona sólo recibió 1.403 sueldos. A.C.A. Real Patrimonio, Maestro Racional, Reg. 1701, f. 5r., 17v. y $29 \mathrm{r}$.

53 PILES ROS, L., Apuntes para la historia económico social de Valencia durante el siglo XV. Valencia, 1969, p. 26.

54 FERRER I MALLOL, M².T., Les aljames sarraines..., p. 130.

55 En 1316 fueron contabilizados 69 musulmanes varones. Se recaudaron 172 sueldos a razón de 2 sueldos 6 dineros por cabeza, ya que la otra mitad del tributo la recibió el consell de Alicante para las obras de las murallas y fueron gravadas 16 moras viudas que a 5 sueldos por cabeza abonaron 80 sueldos. 
sobre el mercado y que en Alicante en 1366 estaba asociado al salmedinatge de los moros $^{56}$.

Caloñas moros. Se recaudo en 1316 como único tributo por valor de 222 sueldos, pero en 1317 se recaudaron las caloñas, el cabezaje y el resto de derechos pagados por los moros de Alicante y de la huerta con un importe de 2.039 sueldos $^{57}$. En 1320 fueron 893 sueldos, en 1321, 2.650 sueldos y en 1324 de 2.807 sueldos $^{58}$.

Renta judicial de la bailía. El baile de Alicante cobro en concepto de renta judicial sobre las multas que había impuesto en $1318,1.522$ sueldos 6 dineros y en 1322 , 2.073 sueldos 7 dineros.

\section{Las rentas de Orihuela}

Orihuela tenía una fiscalidad similar a la de Alicante, con la peculiaridad que en el período estudiado no aparece ningún monopolio real en las cuentas del baile, junto a la ausencia del tercio diezmo. Predominando un impuesto comercial como el almojarifazgo, junto a las cabalgadas y coses vedades, además de las rentas judiciales.

En Orihuela Alfonso X concedió en 1281 el tercio del diezmo al concejo de Orihuela, para la reparación de las iglesias ${ }^{59}$. Además la Corona no percibía la renta de la tahurería, ya que había sido cedida su administración al municipio en época castellana y por que Jaime II en el contexto moralizante de finales del siglo XIII había suprimido la casa de juego ${ }^{60}$. Sancho IV de Castilla había cedido en 1282 al concejo de Orihuela las tahurerías o casas de juego de la villa por tiempo de diez años ${ }^{61}$, y en 1285 realizó una definitiva concesión a perpetuidad. Posteriormente, ya bajo administración catalano-aragonesa Jaime II otorgo en 1296 por un tiempo sujeto a voluntad real esas rentas, siendo poco después las casas de juego suprimidas en el contexto moralizante de la época. Un intento de las autoridades municipales en 1307 por recuperar la tahurería resultó infructuoso por la negativa regia, a pesar de la advertencia de los munícipes de que las prohibiciones no habian menguado la pasión por el juego de los oriolanos y la necesidad del municipio de recaudar esos fondos. En 1325 el Consell de la villa volvió a obtener las rentas de la tahurería, pero al año siguiente el rey redujo su tiempo de vigencia a un sexenio ${ }^{62}$.

56 FERRER I MALLOL, Mํ. T., Les aljames sarraïnes..., pp. 145-146.

57 A.C.A. Real Patrimonio, Maestro Racional, Reg. 1701. FERRER I MALLOL, Mª.T., Les aljames sarraïnes..., p. 131.

58 A.C.A. Real Patrimonio, Maestro Racional, Reg. 1701 y 1702. A.R.V, Bailía, Apéndice 61, ff. $301 \mathrm{r}-302 \mathrm{~V}$.

59 TORRES FONTES, Juan, Colección de documentos para la historia del reino de Murcia. Tomo III. Fueros de Alfonso el sabio a Murcia. Murcia, 1973, Doc. no CXLIX, (1281, marzo, 10), p. 157.

60 BARRIO BARRIO, J.A., "Lo marginal y lo público en Orihuela a través de la acción punitiva del Justicia criminal. 1416-1458», Historia Medieval. Anales de la Universidad de Alicante, 10 (1996), pp. 81-98.

61 ESTAL, J.M., Documentos inéditos de Alfonso $X$ el sabio y del Infante; su hijo Don Sancho. Alicante, 1984. IV parte, Doc. $n^{\circ}$ 8, (1282, mayo, 20), pp. 119-121.

62 FERRER I MALLOL, Mª.T., Organització i defensa d'un territori fronterer..., pp. 164-165. 
El cabezaje de los mudéjares fue concedido por Jaime II al consell de Orihuela en 1296 para destinarlo a la reparación de murallas y torres ${ }^{63}$.

Almojarifazgo. En Orihuela el derecho de almojarifazgo se cobraba tanto a cristianos, musulmanes y judíos. Se incluían los censales que tenía el rey sobre dicho lugar.

Cabalgadas, cosas vedades y caloñas. Bajo la denominación «derecho que pertenece al señor rey de las cabalgadas que se hacen en tierra de moros del rey Granada, cosas vedades y caloñas" se recaudaron 1371 y 2.686 sueldos en 1316 y 1317 respectivamente, sin volver a aparecer en las cuentas de los años siguientes. A partir de 1318 hay una nueva referencia bajo la denominación "emolumentos de la bailía» o rentas judiciales de la bailía y que debe corresponder al mismo concepto. En Orihuela uno de los ingresos de las rentas reales procedía de las cabalgadas organizadas por los lugares del término de Orihuela, ya que de los los ingresos obtenidos en la misma, un quinto correspondía al rey ${ }^{64}$. En el concepto coses vedades se encuentran una serie de productos que habían sido gravados por Jaime I tras la conquista del reino de Valencia, con un canon por su exportación de la ciudad de Valencia y del reino ${ }^{65}$. El número de productos manifestados en la relación de coses vedades fue aumentando con el paso del tiempo ${ }^{66}$. Se incluian metales preciosos, férreos, materias primas, como el alquitrán, maderas, metales, productos alimenticios, armamento, etc. ${ }^{67}$. En la procuración de Orihuela este derecho lo cobraba el baile y afectaba sobre todo a los productos que salían con destino a Castilla.

Renta judicial del justicia de Orihuela. De la renta judicial del justicia de Orihuela recaudada sobre las multas que el magistrado imponía durante el año de su ejercicio, se descontaba el importe del salario del justicia, el de su asesor y el del entregador así como otros gastos no detallados. En 1304 Jaime II Jaime II fijó el salario del justicia de Orihuela en 500 sueldos y el de su asesor en 300. Para el justicia de Alicante estipuló un salario de 400 sueldos y para su asesor 250 sueldos $^{68}$.

Rentas de Cox y de Albatera. Cuando en 1266 Alfonso $X$ delimito el alfoz o término de Orihuela incluyo los lugares de Cox y Albatera como parte de su término ${ }^{69}$.

\section{Ibidem.}

64 ESTAL, J.M. del, El reino de Murcia bajo Aragón (1296-1305). Corpus documental 1/1. Alicante, 1985. Doc. $n^{\circ}$ 51, (1296, mayo, 14), p. 164. Orden de Jaime Il al caballero Gonzalo de Fontana para que exija el pago del quinto del botín de las cabalgadas realizadas en el término de Orihuela. Doc. $n^{\circ}$ 71, (1296, mayo, 18) p. 183. Doc. $n^{\circ}$ 81, (1296, mayo, 21), pp. 190-191.

65 Sobre la exportación de productos en Castilla vid. GONZÁLEZ MÍNGUEZ, C., «"Coses vedades" en Castilla y factores determinantes del desarrollo económico de Vitoria en la Baja Edad Media». Boletín «Sancho el Sabio", Año XXIV, Tomo XXIV, 1980, pp. 179-229.

66 En Castilla las primeras listas de artículos cuya exportación estaba prohibida son de época de Alfonso X. Como en el reino de Valencia en Castilla el número de productos vedados fue aumentando con el paso del tiempo. Así en las Cortes de 1313 la relación se ha ampliado considerablemente. Ibidem, pp. 183-184.

67 HINOJOSA MONTALVO, J., "Coses vedades», Diccionario histórico de la Comunidad Valenciana, Valencia, 1992.

68 A.C.A. C, reg. 231, f. 56r. (1304, diciembre, 5).

69 TORRES FONTES, J., Codom. T. III. pp. 89-91. 1266, julio, 15. 
En 1296 Albatera y Cox eran lugares señoriales que pertenecían al arráez de Crevillente. En 1318 Jaime Il incorporó el señorío de Crevillente a la Corona hasta que el 22 de mayo de 1322 lo dono al infante Pedro ${ }^{70}$. Tras la desaparición del señorío musulmán de Crevillente en 1318 Jaime II concedió dichos lugares en 1320 a Acard de Mur ${ }^{71}$. A pesar de ello las rentas de Cox y Albatera fueron cobradas por el Baile en 1322 (4.100 sueldos) y 1324 (2000 sueldos) dentro de las rentas del Patrimonio Real. En las cuentas de 1324 la anotación indica que el baile recibe 2.000 sueldos de las rentas de Cox y de Albatera por composición realizada con los herederos del noble Acard de Mur ${ }^{72}$.

Otras rentas. Como rentas de menor importancia señalar el march de plata, como en Alicante, con un valor fijo de 120 sueldos anuales y la renta de los judíos de Orihuela que pagaban un canon fijo anual como sus correligionarios de Elche, y que como hemos destacado anteriormente se repartía entre ambas juderías pagando la de Orihuela 500 sueldos anuales, cifra superior a la de Elche y que apunta la mayor pujanza de la comunidad israelita oriolana.

En 1316 aparece un pago de 84 sueldos en concepto de herbaje, por algunas cabañas que pasaron el puente de dicho lugar y por 14 cabezas que fueron vendidas a un judío y a un moro a razón de 6 sueldos por cabeza.

\section{Las rentas de Guardamar}

Durante el período estudiado Guardamar era una villa real. Según Ferrer i Mallol fue un núcleo exclusivamente cristiano, a pesar de un frustrado intento de Jaime II en 1298 para crear un morería en la localidad ${ }^{73}$.

Por la escasa importancia de Guardamar y al no contar con población sarracena, las rentas se arrendaban anualmente por una cantidad fija. Las rentas recaudadas en esta localidad eran las más bajas de la procuración. En 1316 fueron arrendadas a Bernat Macip vecino del lugar por 1.100 sueldos. El segundo concepto por el que percibía ingresos la Corona era por las rentas judiciales, tanto del justicia como las del baile del lugar. En 1316 se produjo un ingreso excepcional de 1.000 sueldos por la muerte de un musulmán. La pena judicial impuesta a los cristianos culpables del homicidio, ascendía a dos mil sueldos, de los que mil correspondían al rey y la otra mitad a la familia del mudéjar asesinado, que no acepto la indemnización ya que la Suna les prohibía cobrar por la muerte de su familiar ${ }^{74}$.

70 Sobre el señorío musulmán de Crevillente vid. GUICHARD, P., Un señor musulmán en la España cristiana: el "ra'is" de Crevillente (1243-1318). Alicante, 1976. FERRER I MALLOL, Má.T., Les aljames sarraïnes..., pp. 16-22 y 33-34.

71 FERRER I MALLOL, M…, Les aljames sarraines..., pp. 7-8.

72 A.C.A. Real Patrimonio, Maestro Racional, Reg. 1702.

73 FERRER I MALLOL, Mํ.T., Les aljames sarraines de la Governació d'Oriola en el segle XIV. Barcelona, 1988. p. 5. Id. La frontera amb l'islam en el segle XIV. Cristians i sarraïns al País Valencià. Barcelona, 1988, pp. 6 y 15.

74 A.C.A. Real Patrimonio, Maestro Racional, Reg. 1701, f. 6r. Sobre este episodio vid. FERRER I MALLOL, Mª.T., Les aljames sarraïnes..., p. 166. 
RENTAS REALES DE ELCHE, CREVILLENTE, ALICANTE, ORIHUELA Y GUARDAMAR AÑOS 1316-1319. VALOR PORCENTUAL

\begin{tabular}{|l|c|c|c|c|c|c|c|c|}
\hline RENTAS & \multicolumn{2}{|c|}{$\begin{array}{c}\text { AÑO 1316 } \\
\text { (mayo a diciembre) }\end{array}$} & \multicolumn{2}{|c|}{ AÑO 1317 } & \multicolumn{2}{c|}{ AÑO 1318 } & \multicolumn{2}{c|}{ AÑO 1319 } \\
\hline RENTAS & SUELD & $\%$ & SUELD & $\%$ & SUELD & $\%$ & SUELD & $\%$ \\
\hline Elche & 43.521 & 75,49 & 68.913 & 77,54 & 59.158 & 71,42 & 53.257 & 53,2 \\
\hline Crevillente & - & - & - & - & 12.604 & 15,22 & 30.147 & 30,12 \\
\hline Alicante & 6.208 & 10,77 & 9.692 & 10,91 & 10.244 & 12,37 & 9.160 & 9,15 \\
\hline Orihuela & 5.688 & 9,87 & 8.822 & 9,93 & 8.167 & 9,86 & 6.095 & 6,09 \\
\hline Guardamar & 2.233 & 3,87 & 1.448 & 1,63 & 2.657 & 3,21 & 1.440 & 1,44 \\
\hline TOTAL ABS. & 57.651 & - & 88.875 & - & 82.831 & - & 100.099 & - \\
\hline
\end{tabular}

Fuente: A.C.A. Real Patrimonio, Maestro Racional, Reg. 1701.

RENTAS REALES DE ELCHE, CREVILLENTE, ALICANTE, ORIHUELA Y GUARDAMAR. AÑOS 1320-1324. VALORES PORCENTUALES

\begin{tabular}{|l|c|c|c|c|c|c|c|c|}
\hline RENTAS & \multicolumn{2}{|c|}{ AÑO 1320 } & \multicolumn{2}{c|}{ AÑO 1321 } & \multicolumn{2}{c|}{ AÑO 1322 } & \multicolumn{2}{c|}{ AÑO 1324 } \\
\hline RENTAS & SUELD & $\%$ & SUELD & $\%$ & SUELD & $\%$ & SUELD & $\%$ \\
\hline Elche & 78.869 & 66,19 & 49.695 & 58,45 & 78.052 & 79,23 & 55.257 & 77,07 \\
\hline Crevillente & 25.448 & 21,36 & 18.138 & 21,33 & - & - & - & - \\
\hline Alicante & 7.303 & 6,13 & 9.035 & 10,63 & 8.953 & 9,09 & 6.573 & 9,17 \\
\hline Orihuela & 6.154 & 5,16 & 6.510 & 7,66 & 10.486 & 10,64 & 9.264 & 12,92 \\
\hline Guardamar & 1.379 & 1,16 & 1.640 & 1,93 & 1.020 & 1,04 & 600 & 0,84 \\
\hline TOTAL ABS. & 119.155 & 2 & 85.019 & 1 & 98.512 & 7 & 71,695 & 1 \\
\hline
\end{tabular}

Fuente: A.C.A. Real Patrimonio, Maestro Racional, Reg. 1701. 


\section{Balance global de las rentas reales en la Procuración}

Lo más destacado de las rentas reales en la procuración de Orihuela es el perfil diferenciado que presentan respecto a las del resto de localidades del reino de Valencia, como ya ha sido puesto de manifiesto para inicios del siglo XV por Enric Guinot ${ }^{75}$. Destacar la ausencia en las villas reales de la bailía de tributos habituales en otras localidades reales de la Corona de Aragón y del reino de Valencia como la quèstia/ peita, la cena, o como el yantar o los pedidos castellanos ${ }^{76}$. Fruto de las exenciones y franquicias fiscales de época castellana.

Dentro de la contribución de cada villa al conjunto de rentas reales, destacan las rentas de la villa de Elche, que llegaron a suponer el $79 \%$ del total recaudado. En segundo lugar Crevillente que con su breve incorporación al patrimonio real aporto importantes cantidades al fisco real. Localidades de población cristiana mayoritaria como Alicante y Orihuela realizaban una aportación mucho menor a las arcas reales, mientras que las rentas obtenidas en la pequeña villa de Guardamar no dejaban de ser simbólicas por las exiguas cantidades que se colectaban.

\section{LOS GASTOS}

Los gastos más destacados que tenía que realizar el baile en nombre de la Corona correspondían al pago a los alcaides por la tenencia de los castillos y los salarios de los oficiales reales ${ }^{77}$. Recalcar también las partidas destinadas a provisión de la casa real o para algún miembro de la familia real. En un segundo plano aparecen el pago de violarios y deudas, obras, donaciones y gastos extraordinarios.

El control de los gastos era realizado por el propio rey, que expedía la correspondiente orden al baile estableciendo los pagos fijos que debía realizar en nombre de la Corona. El 18 de diciembre de 1317 Jaume II tras comprobar los ingresos que se habían producido en las rentas de la bailía dellà Xixona, ordenaba a Jaume Andreu, nombrado ocho días antes como Baile general de dicha demarcación ${ }^{78}$, los pagos que debía realizar en 1318, fijando en primer lugar el pago del salario de cada uno de los alcaides de los castillos reales del territorio y el salario de cada uno de los oficiales reales, escribanos, colectores, la satisfacción de la pensión anual a cada uno de los titulares de violarios comprados por la Corona, etc. ${ }^{79}$.

75 GUINOT, E., «El patrimoni reial al Pais Valencià...», p. 612. Para la fiscalidad real en Cataluña vid. SÁNCHEZ MARTÍNEZ, M., El naixement de la fiscalitat d'Estat a Catalunya (segles XII-XIV), Vic, 1995.

76 Para la fiscalidad real en Castilla vid. LADERO QUESADA, M.A., Fiscalidad y poder real en Castilla (1252-1369), Madrid, 1993.

77 Como ya ha sido puesto de manifiesto para el reino de Valencia y en la primera década del siglo XIV por Christian GUILLERÉ en "Les finances de la Couronne d'Aragon au debut du XIVe siecle...", p. 492.

78 Parece ser que el día 10 de diciembre de 1317 ya había sido nombrado para el cargo. FERRER I MALLOL, Mํ.T., "La Batllia general de la part del regne de Valencia dellà Xixona...», pp. 287-288.

79 A.R.V. Bailía, Apéndice 61, ff. 304r-v (1317, diciembre, 18). 


\section{Salarios y tenencias de Castillos}

Sobre el documento citado anteriormente y la comprobación de los gastos realizados por los correspondientes bailes en el período estudiado podemos detallar la partida de gastos fijos de la Corona en pago de tenencia de castillos y salarios a oficiales reales.

En concepto de tenencia de castillos el baile pagaba a cada uno de los alcaides el salario correspondiente. El del castillo de Orihuela cobraba 6.000 sueldos desde 1313. El de Callosa 800 sueldos. El de Guardamar 1.000 sueldos en 1316, cifra que se redujo a 500 a partir de 1318. El alcaide de la calahorra de Elche cobro 1.000 sueldos en el período contabilizado y el de Alicante 5.000 sueldos $^{80}$.

A estas cifras hay que sumar los salarios cobrados anualmente por los oficiales reales. A los titulares que ejercieron la procuración real entre 1316 y 1324 les fue asignado un salario de 4.000 sueldos, excepto Arnau de Torrelles que ocupo el cargo entre 1313 y agosto de 1316 y que tenía asignado un salario de 2.000 sueldos $^{81}$, como queda recogido en las cuentas del baile de $1316^{82}$. El asesor de la procuración disponía entre 1316 y 1324 de un salario diario de 4 sueldos, que correspondía al mantenimiento de dos cabalgaduras, lo que suponía al año un monto de 1460 sueldos $^{83}$.

Asimismo los oficiales de la bailía tenían asignadas unas atribuciones anuales. El titular de la bailía general del reino de Valencia dellà Xixona cobraba 2.000 sueldos anuales desde $1304^{84}$, el baile local de Orihuela 300, el de Alicante y el de Guardamar 200 cada uno. Jaume Descaplers, vecino de Elche, ocupo la escribanía de la bailía desde 1316 y hasta 1327, con un salario de 200 sueldos $^{85}$. El titular de la bailía general del reino de Valencia, Ferrer Descortell, Baile general del reino de Valencia desde $1316^{86}$, tenía en 1316 y 1317 una asignación de 13.920 sueldos, sobre las rentas de Elche, en concepto de pago de violarios y por la tenencia de algunos castillos del reino ${ }^{87}$ y que no recibió en 1324. El lugarteniente del Baile no obtenía un salario fijo y

80 Sobre el sistema de tenencia y el salario de los alcaides de los castillos de la frontera meridional de Alicante en el siglo XIV vid. FERRER I MALLOL, M". T., "La tinença a costum d'Espanya en els castells de la frontera meridional valenciana (segle XIV)», Miscel.lània de Textos Medievals, 4 (1988), pp. 1-102.

81 Sobre los procuradores que ejercieron el cargo entre 1316 y 1324 vid. FERRER I MALLOL, Ma.T., Organització i defensa d'un territori fronterer..., pp. 84-115.

82 A.C.A. Real Patrimonio, Maestro Racional, Reg. 1701, f. 8 r.

83 En 1316 el asesor Llorenç Fritós ya recibió este salario que se mantuvo hasta 1324 en que Guillem Mir percibió la misma cantidad. A.C.A. Real Patrimonio, Maestro Racional, Reg. 1701, f. 9v. Reg. 1702, f. 7V.

84 FERRER I MALLOL, M ${ }^{a}$.T., "La Batllia general de la part del regne de Valencia dellà Xixona...», p. 283.

85 Ibídem, p. 299.

86 FERRER I MALLOL, Mª .T., “La Batllia general de la part del regne de Valencia dellà Xixona...», p. 285.

87 A.C.A. Real Patrimonio, Maestro Racional, Reg. 1701, f. $11 \mathrm{~V}$. 
al titular de 1317 Bertomeu Romeu, la Corona le asignó 150 sueldos anuales para mantener al servicio del rey un caballo alforrado ${ }^{88}$.

Con un salario de 10 sueldos diarios el escribano del puerto de Alicante, percibía anualmente la cifra de 304 sueldos, incrementada en 1324 a 400 sueldos.

Desde 1318 la bailía general dellà Xixona contó con un abogado asesor. El nombramiento había sido solicitado por el titular de la bailía ante la necesidad de contar con un jurista. Bernat de Solsona, vecino de Alicante, ejerció desde 1318 con un salario anual de 100 sueldos. El cargo fue sustituido en 1324 , ya que se recupero la figura del Procurador Fiscal en la persona de Guillem Fibla con un salario de 100 sueldos ${ }^{89}$.

Alfonso Guillem colector de los impuestos de los mudéjares de Elche cobro en el período contable 1316-1324, 400 sueldos por su actividad. Le fue concedido el oficio de colector por Jaime II en enero de 1308 y de forma vitalicia en $1311^{90}$. Aunque según María Teresa Ferrer i Mallol Jaime II había pedido en 1313 al Baile General dellà Xixona que permitiese que el oficio fuese ejercido por Juçef Capdepebre. En 1316 como consta en las cuentas del Baile de dicho año Alfonso Guillem seguía ejerciendo su oficio como colector. Entre sus obligaciones estaba la de «... reebre les comptes dels moros en morisc e per fer trasladar en crestianesc les libres de les rendes d'Elx...". Cobraba como recaudador real una gama variada de rentas sobre los mudéjares de Elche, que si no se vendían eran recaudadas por un colector real: Almagram, alfarda, diezmo del pan, del vino y del aceite y otros frutos, agua, cabezaje, albayat, alhabeç de las mezquitas, alfatrà, gallinas y atzaque. En las cuentas de 1323 aparece cobrando un salario Juçef Capdepebre de 150 sueldos por la "turçimanyia» de los moros de Elche. El salario había sido asignado por Jaime II en 1321, en reconocimiento a la tarea que venia realizando desde años como trujamán de los impuestos de los sarracenos ${ }^{91}$.

Los 180 sueldos anuales del alcadí de la aljama de moros de Elche era en concepto de salario por el cargo y por redactar el padrón para la recaudación de la alfarda92.

"Item al alcadi de les moros d'Elx per salari de la dita alcaydia e per escriure los padrons de la alfarda de les moros segons es acostumat... CLXXX solidos" ${ }^{93}$.

Cada año un mudéjar de Elche recibía 100 sueldos por la ayuda que prestaba en el cobro de caloñas e impuestos que gravaban la comunidad mudéjar de Elche.

88 FERRER I MALLOL, $\mathrm{M}^{2}$.T., «La Batllia general de la part del regne de Valencia dellà Xixona...», p. 298. A.C.A. Real Patrimonio, Maestro Racional, Reg. 1701, f. $33 \mathrm{v}$.

89 Ibidem, pp. 298-299. A.C.A. Real Patrimonio, Maestro Racional, Reg. 1702, f. 8r.

90 FERRER I MALLOL, M‥T., Les aljames sarraines..., pp. 176-177 y Doc. $n^{\circ}$ 34, (1308, enero, 16), p. 203-204.

91 FERRER I MALLOL, Mํ.T., Les aljames sarraines..., p. 177.

92 FERRER I MALLOL, Mํ.T., Les aljames sarraines..., p. 178.

93 A.C.A. Real Patrimonio, Maestro Racional, Reg. 1702, f. $7 \mathrm{v}$. 


\begin{tabular}{|c|c|c|c|}
\hline \multirow[t]{2}{*}{ CONCEPTO } & \multicolumn{3}{|c|}{ AÑOS } \\
\hline & 1316 & 1317 & 1324 \\
\hline Alcaide Castillo Orihuela & 6.000 & 6.000 & 6.000 \\
\hline Alcaide Castillo Callosa & 800 & 800 & 800 \\
\hline Alcaide Castillo Guardamar & 1.000 & 1.000 & 500 \\
\hline Alcaide Calahorra Elche & 1.000 & 1.000 & 1.000 \\
\hline Alcaide Castillo Alicante & 5.000 & 5.000 & 5.000 \\
\hline Salario Procurador & 2.000 & 4.000 & 4.000 \\
\hline Asesor de la Procuración & 1.460 & 1.460 & 1.460 \\
\hline Baile Gral. Reino Valencia & 13.920 & 13.920 & - \\
\hline Baile Gral. dellà Xixona & 2.000 & 2.000 & 2.000 \\
\hline Baile de Orihuela & 300 & 300 & 300 \\
\hline Baile de Alicante & 200 & 200 & 200 \\
\hline Baile Guardamar & 100 & 100 & 100 \\
\hline Escribano de la Bailía & 200 & 200 & 200 \\
\hline Escribanía Puerto Alicante & 304 & 304 & 400 \\
\hline Colector de la renta de los Mudéjares de Elche & 400 & 400 & 400 \\
\hline Alcadí de la Aljama de los moros de Elche & 180 & 180 & 180 \\
\hline $\begin{array}{l}\text { Un moro de Elche que ayuda en la Alfarda y } \\
\text { en las caloñas de los moros }\end{array}$ & 100 & 100 & 100 \\
\hline Guarda del Molinello & - & 200 & 200 \\
\hline Salario Procurador Fiscal & - & - & 100 \\
\hline Salario de un trujamán & - & - & 150 \\
\hline TOTAL & 36.964 & 39.164 & 25.090 \\
\hline
\end{tabular}

Fuente: A.C.A. Real Patrimonio, Maestro Racional, Reg. 1701, 1702. A.R.V. Bailía, Apéndice 61, ff. 303r-v. 
"Item an Jahie Alluben moro d'Elx los quals pren cascun any per la ajuda que fa en les calonies e en les alfardes que.ls moros pagen cascun any segons es acostumat... C solidos" ${ }^{94}$.

El molinello era un puesto de vigilancia del camino entre Alicante y Jijona y situado en el límite del término. Al menos desde 1306 el responsable de la custodia del puesto percibía una salario anual de 200 sueldos. Durante el período estudiado ocupo el cargo Pere Miquel de Vaylo entre 1306 y hasta su muerte en 1323 . Fue sustituido por su hijo Martí Pérez de Vaylo ${ }^{95}$.

El pago de salarios a los oficiales reales y a los alcaides por la tenencia de castillos supuso en los tres años contabilizados una de las partidas más importantes ya que absorbió en 1316 el $40 \%$ en 1317 el $38 \%$ y en 1324 el $30 \%$ del presupuesto total de gastos.

\section{Provisión de la casa real}

Para provisión de la casa real conocemos para los años 1316 y 1317 una partida anual fija de 31.500 sueldos para gastos de la casa real96.

A partir de 1324 desaparece esta partida y es sustituida por una asignación anual al infante Pedro, de 45.000 sueldos sobre las rentas de Elche, concedida por Jaime II. Aunque el 6 de mayo de dicho año se produjo la donación solemne del lugar al infante Ramón Berenguer, manteniendo el infante Pedro la renta ${ }^{97}$. Mientras que en las cuentas de 1324 se consigna una partida destinada al Infante don Pedro, de 36.300 sueldos que el rey le ha concedido sobre las rentas de Elche, aunque cobro 35.200 sueldos ya que hubo que descontar el pago de un violario.

La partida de gastos dedicada a la casa real era una de la más importantes. En 1316 y 1317 en concepto de provisión real supuso el 40'7 y el 38'4\% respectivamente. Mientras que en 1324 la cantidad asignada al infante don Pedro represento el $46 \%$ del total de gastos.

La suma de las partidas de salarios y provisión de la casa real representaba en 1316 el $79 \%$, en 1317 el $73,7 \%$ y en 1324 el $76 \%$.

\section{Violarios y deuda}

Todos los años una parte de los gastos de la bailía se empleaban en pagar las pensiones de los violarios que había adquirido la Corona en el territorio. El violario era una modalidad de crédito encubierta, muy parecida al censal, pero que a diferencia

94 A.C.A. Real Patrimonio, Maestro Racional, Reg. 1702, f. 7v.

95 FERRER I MALLOL, M…, Organització i defensa d'un territori fronterer..., pp. 320-321.

96 Que recaudaba el tesorero real Pere March. Para las partidas contabilizadas de 1316 y 1317 aparecen 20.000 y 30.500 sueldos respectivamente que el baile entrego al tesorero real Pere March para provisión de la casa real.

97 FERRER I MALLOL, Mª.T., Les aljames sarraines..., pp. 34-35. 


\begin{tabular}{|l|c|c|c|}
\hline BENEFICIARIO & \multicolumn{3}{|c|}{ PENSIÓN ANUAL } \\
\hline & 1316 & 1317 & 1324 \\
\hline Berenguer de Puigmolto & 1.000 & 1.000 & - \\
\hline Pons de Mataro & 1.500 & 1.500 & - \\
\hline Domingo Ponçano & 1.000 & 1.000 & - \\
\hline Joan Galbe & 1.000 & 1.000 & 1.000 \\
\hline Joan Pérez de Vesques & 500 & 500 & 500 \\
\hline Urrigo de Quintanall & 1.000 & 1.000 & 1.000 \\
\hline Pere Andreu d'Odena & 500 & 500 & - \\
\hline Pere Monpaho & 250 & 250 & $243 \mathrm{~s}$. \\
\hline $\begin{array}{l}\text { Jaume Masquefa, como proc. de los herederos } \\
\text { de Guillem Paratge }\end{array}$ & 7.000 & 7.000 & $3.243 \mathrm{~s}$. \\
\hline $\begin{array}{l}\text { TOTAL } \\
\text { Guillem Soler }\end{array}$ & 250 & 250 & - \\
\hline
\end{tabular}

Fuente: A.C.A. Real Patrimonio, Maestro Racional, Reg. 1701, ff. 10v-11r. 20r-21r. Reg. 1702, f. 7r.

de éste no era perpetuo, sino que el pago de la pensión anual se limitaba a la vida de dos personas señaladas por las partes, siendo frecuente tomar como referencia la vida de miembros de la casa real.

La cifra que debía pagar anualmente el baile de las rentas del territorio a dueños de los violarios en 1316 y 1317 , se elevaba a 7.000 sueldos. Jaime II comunicaba a Jaume Andreu días después de ser nombrado para el cargo de Baile general del reino de Valencia dellà Xixona, el nombre de los dueños de los violarios y de la pensión anual que debía pagar a cada uno de ellos ${ }^{98}$. En 1324 algunos violarios ya se habían extinguido y sólo hay uno nuevo, pasando la cifra global a pagar en concepto de pensiones de 7.000 a 3.243 sueldos.

98 A.R.V. Bailía, Apéndice 61, ff. 304r-v (1317, diciembre, 18). 
El baile también tenía que hacer frente a diversas deudas de las arcas reales, normalmente a oficiales reales o a servidores de la casa real. En el primer grupo incluir los pagos de 500 sueldos pendientes a un escribano real en 1316 y los 5.000 sueldos que cobro el titular de la bailía en 1317 de un préstamo que había realizado a la Corona. En 1317 y 1324 los pagos por deudas de la Corona fueron superiores a la amortización de las pensiones anuales de los violarios.

\section{Gastos en obras}

Para los tres años que disponemos de cuentas de gastos, las partidas de obras, corresponden a diversas inversiones realizadas en el castillo de Orihuela (463 sueldos en 1316 y 1021 en 1317), el almudín de Alicante (947 sueldos en 1316), el castillo de Alicante con 1591 sueldos en 1317, la torre del cap del Aljup (228 sueldos en 1316 y 1106 en 1324) ${ }^{99}$. Una serie de partidas menores al alcázar de Elche (479 sueldos en 1324), los muros del arrabal de Elche, el castillo de Callosa y el castillo de Guardamar.

\section{Gastos en Administración}

He incluido en este apartado una serie de pequeños y variados gastos destinados al mantenimiento del aparato burocrático de la bailía, siendo los más destacados los correspondientes al pago de las prendas de vestir de los correos, con asientos contables de 85 sueldos por correo, para capa, camisa y pantalones. En 1316 recibieron este pago cinco correos y en 1317 ocho $^{100}$.

Otros gastos en este apartado tuvieron como fin el pago de dietas a oficiales reales como el propio baile o el alcaide del castillo de Orihuela, o el alquiler de casas para almacenar el producto de los diezmos.

Añadir a estos gastos el pago que cada año se realizaba en correos, escrituras y otras "coses necessaries al fet» de la bailía ${ }^{101}$.

\section{Donaciones reales}

Desde el inicio de la conquista del reino de Murcia Jaime It recompenso a diversos caballeros fieles con heredades, rentas o pensiones anuales. Las cuentas estudiadas recogen algunas de estas donaciones efectuadas por Jaime $\|^{102}$. El resto son peque-

99 Las obras de 1324 se realizaron “... en les botigues en que les mercaders meten la roba e mercaderies lurs...», A.C.A. Real Patrimonio, Maestro Racional, Reg. 1702, f. 9 r.

100 En 1317600 sueldos se destinaron al pago de las prendas de vestir de dos escribanos reales.

101 A.C.A. Real Patrimonio, Maestro Racional, Reg. 1701, f. 13 r.

102 Felipe Togores recibió 1.000 sueldos para una cabalgadura, aunque sólo en las cuentas de 1316, la entrega de 200 sueldos que tenía pendientes de dicha cantidad. A.C.A. Real Patrimonio, Maestro Racional, Reg. 1701, f. $11 \mathrm{v}$. 
ñas ayudas para mantenimiento de cabalgaduras y donativos reales. Son cifras insignificantes y que suponen unos porcentajes paupérrimos sobre el total de gastos.

\section{Gastos varios}

Uno de los gastos varios era el pago de una cantidad anual fija al Obispo y Capítulo de Cartagena, en concepto de diezmo de las rentas de Elche y del puerto de Santa Pola y que se abonaba en dos plazos de 400 sueldos (habitualmente en Mayo y Octubre) ${ }^{103}$.

En este apartado también hay que incluir diversas compras realizadas por el baile como la de 30 «stores» que se enviaron a Barcelona, o la de 6 «stores" y 2 mesas en 1317.

Determinados pagos extraordinarios engrosan esta partida de varios, como los 579 sueldos que tuvo que abonar en 1317 el baile a un vecino de Alicante, por un caballo que había perdido en Almería al servicio del rey.

También hay que considerar dentro de los gastos los atrasos que resolvía anualmente el baile, como los 3013 sueldos que tenía pendientes de cobro en 1316, ya que en un ejercicio anterior había pagado de su peculio esa cantidad al resultar las cuentas de la bailía deficitarias ${ }^{104}$.

"Item mes en dat lo dit en Johan Raolf los quals li romaseren a cobrar del compte segons que avia mes dat que no avia reebut segons que en 10 dit compte es declarat...".

Por el mismo motivo en 1324 el baile cobro 1687 sueldos de las cuentas del año anterior $^{105}$.

\section{Balance global de los gastos de las rentas reales en la Procuración}

Lo más reseñable en un balance global sobre el gasto de las rentas reales en la procuración real de Orihuela, es que la mayor parte iban destinadas al pago del salario de alcaides y oficiales reales, así como a miembros de la casa real. Empleándose el resto de partidas en el pago de deudas contraídas en el territorio, pequeños gastos de burocracia, donaciones reales, etc.

El pago de salarios de alcaides y oficiales suponía porcentajes que iban del $30 \%$ de 1324 al $40 \%$ de 1316, mientras que para provisión de la casa real en 1316 y 1317 el porcentaje fue del 38 y el $35 \%$ respectivamente. En 1324 la renta para provisión del infante don Pedro supuso el $46 \%$ de los gastos de las rentas reales del territorio. Por tanto las tres cuartas partes de las rentas reales correspondían al mantenimiento de la administración real en el territorio procuratorial y a la provisión de la casa real. Partidas como las de obras en los castillos tuvieron una mínima significación, ya que la Corona

103 A.C.A. Real Patrimonio, Maestro Racional, Reg. 1701, f. 19v.

104 A.C.A. Real Patrimonio, Maestro Racional, Reg. 1701, f. 11v.

105 A.C.A. Real Patrimonio, Maestro Racional, Reg. Reg. 1702, f. 10r. 
GASTOS EFECTIVOS DE LAS RENTAS REALES. (1316-1324)

${ }^{*}$ = Gastos correspondientes a ocho meses (sólo para 1316)

\begin{tabular}{|c|c|c|c|c|c|c|c|c|c|}
\hline \multirow{3}{*}{ CONCEPTO } & \multicolumn{9}{|c|}{ AÑOS } \\
\hline & \multicolumn{3}{|c|}{$1316^{\star}$} & \multicolumn{3}{|c|}{1317} & \multicolumn{3}{|c|}{1324} \\
\hline & SUELD. & D. & $\%$ & SUELD. & D. & $\%$ & SUELD. & D. & $\%$ \\
\hline $\begin{array}{l}\text { Tenencias de } \\
\text { castillos y salarios }\end{array}$ & 22248 & 4 & 40,74 & 35385 & 3 & 38,44 & 22955 & 6 & 30,05 \\
\hline $\begin{array}{l}\text { Provisión de la } \\
\text { Casa Real }\end{array}$ & 20900 & & 38,27 & 32497 & 11 & 35,3 & 一 & 一 & - \\
\hline $\begin{array}{l}\text { Provisión Infante } \\
\text { D. Pedro }\end{array}$ & - & 一 & - & - & - & 一 & 35200 & 一 & 46,08 \\
\hline Violarios y deuda & 5160 & & 9,45 & 15017 & 9 & 16,32 & 9257 & 10 & 12,12 \\
\hline Obras & 1638 & 3 & 3 & 2813 & 4 & 3,06 & 1960 & 7 & 2,57 \\
\hline $\begin{array}{l}\text { Mantenimiento } \\
\text { burocracia }\end{array}$ & 787 & 3 & 1,44 & 2727 & 1 & 2,96 & 1528 & 9 & 2 \\
\hline Donaciones reales & 200 & - & 0,36 & 1475 & - & 1,6 & 2845 & - & 3,72 \\
\hline Gastos varios & 3675 & 8 & 6,73 & 2127 & - & 2,31 & 2637 & - & 3,45 \\
\hline Subtotal & 54608 & 18 & & 92041 & 28 & & 76382 & 32 & \\
\hline TOTAL & 54609 & 6 & & 92043 & 4 & & 76384 & 8 & \\
\hline
\end{tabular}

Fuente: A.C.A. Real Patrimonio, Maestro Racional, Reg. 1701 y 1702. Elaboración propia.

había concedido a las villas reales del territorio determinadas rentas como el cabezaje - la tahurería para que pudieran invertir lo recaudado en obras de muros y torres.

Como apunte final destacar que la principal prioridad de la Corona en el gasto de las rentas en el territorio, fue librar cada año puntualmente el salario de los alcaides de los respectivos castillos. Por ello Jaime II en la orden remitida al inicio de su mandato al baile general Jaume Andreu, situaba en la prelación de gastos en primer lugar el salario de cada uno de los alcaides. En las cuentas de gastos se señala siempre en primer lugar el pago a los alcaides por la tenencia de los castillos, que se solía satisfacer integro durante el ejerció anual del cargo. El pago de los salarios a los oficiales reales resulto más irregular, lo que demuestra que en el gobierno del territorio la principal prioridad de la Corona era asegurar el control de los castillos.

Durante el período estudiado Jaume II pudo asegurar en la procuración de Orihuela el control militar y la administración real gracias a las rentas cobradas en el territorio. Además desvió una parte sustanciosa de las mismas a engrosar las arcas de la Corona o las de algún miembro destacado de la familia real como el infante don Pedro. 